\title{
Pancreatic Intraductal Papillary Mucinous Neoplasms.... Still Unanswered Questions!
}

\author{
Sébastien Gaujoux ${ }^{1,2}$
}

'Department of Pancreatic and Endocrine Surgery, Cochin Hospital, APHP, Paris, France ${ }^{2}$ Facultı de Mıdecine Paris Descartes, Universitı Paris Descartes, Sorbonne Paris Citı

\section{INTRODUCTION}

Pancreatic intraductal papillary mucinous neoplasms (IPMN) are one of the precursors lesions of pancreatic adenocarcinoma. They have only been individualized as a specific disease in the mid 80's and were first recognized by the World Health Organization in 1996. Since then, significant progress has been made in the diagnosis, understanding of the natural history and management of this frequent pancreatic neoplasm. Nevertheless, there are still numerous unanswered questions that make difficult patients management.

\section{Pancreatic cyst "epidemic"}

With the widespread use of high-quality cross-sectional imaging, an increased number of asymptomatic cystic pancreatic lesions are being identified. The prevalence of these so called "incidentalomas", i.e. asymptomatic lesion fortuitously detected by imaging, is approximately $10 \%(1)$ in the population and may reach as high as $30 \%$ in older patients (2). Pancreatic cystic incidentaloma encompasses a wide spectrum of neoplasms, including serous cystadenomas (SCA), mucinous cystic neoplasms (MCN), mucinous cystadenocarcinomas, nonfunctional neuroendocrine tumors (PNET), solid and pseudopapillary neoplasm (SPPN) and intraductal papillary mucinous neoplasms (IPMN) (3).

The main issue in cystic pancreatic lesions management is that beyond their comforting presentation, this heterogeneous group of lesions can be premalignant or even malignant (Fig. 1). This concern has led to an increasing number of resections for pancreatic incidentaloma in order to eradicate potentially threatening pancreatic lesions in their earliest stages.

\section{The diagnostic issue...}

A "pancreatic cyst" is NOT a diagnosis. Knowing that there is various kind of pancreatic cystic lesions carrying different risk of cancer, having an accurate diagnosis is mandatory before any medical decision. You should always know what you are watching... you should always know what you are resecting. Nevertheless, even in high volume centers, there is in all surgical series, i.e.
Corresponding author:

Professeur Sebastien Gaujoux, MD, PhD Department of Digestive, Hepato-biliary and Endocrine Surgery, Cochin Hospital, APHP, Universitt Paris Descartes, Paris

27, rue du Faubourg Saint Jacques,

75014, Paris, France

Tel.: 0033158411715

Fax: 0033158412962

E-mail: sebastien.gaujoux@aphp.fr

\section{Abbreviations:}

IPMN - intraductal papillary mucinous neoplasms;

SCA - serous cystadenomas;

MCN - mucinous cystic neoplasms; PNET - non-functional neuroendocrine tumors.

Received: 31.10 .2019

Accepted: 02.12.2019

Copyright (1) Celsius Publishing House www.sgo-iasgo.com 
Figure 1 - Various cystic pancreatic lesions

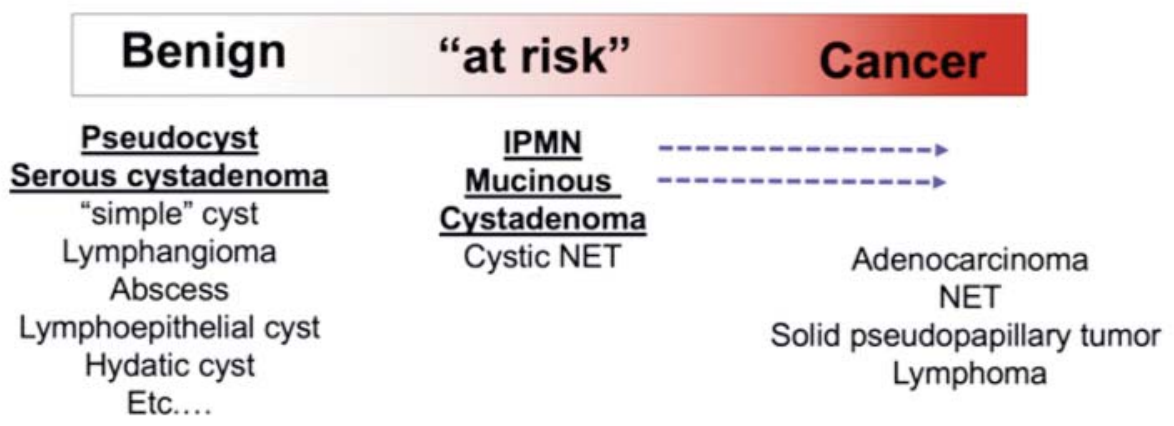

already highly selected patients, a discrepancy between the supposed preoperative diagnosis and the final pathological diagnosis, in about $20 \%$ (2). This should always be kept in mind when we select patients for surgery, and make the assessment of the benefit risk balance, especially for small asymptomatic pancreatic cyst.

\section{The benefit risk balance of surgery... what you need to know!}

Pancreatic surgery can be seen as one of the most challenging surgery, because it is technically challenging, but more importantly because of the need of multiple skills in the management of these patients, including surgeons, gastroenterologist, diabetologist, oncologist, pancreatologist, radiologists, interventional radiologist, pathologist, psychologist and nutritionist. The mortality of pancreatic surgery ranges from $1 \%$ to $3 \%$ in high-volume centers $(4,5)$, but increases up to 6 to $10 \%$ when nationwide centers are considered (6-8). Considering these hetero-geneous results, there is a benefit to be managed in high volume centers $(3,4,5)$.

\section{What are IPMN?}

Intraductal papillary mucinous neoplasms (IPMN) are cystic pancreatic mucin-producing neoplamsm. Histologically, they are categorized according to their localization (main duct, branch duct involvement or both), their grade of dysplasia (low or high) and their phenotype (gastric, intestinal, pancreaticobiliary or oncocytic) $(7,8)$. Their clinical management remains challenging, only based on imaging features and clinical symptoms $(9,10)$. The molecular basis of IPMN remains poorly defined however it is now believed that both MD-IPMN and BD-IPMN carry a variable but measurable risk of cancer progression, ranging from
57-95\% and 6-46\%, for MD-IPMN and BD-IPMN, respectively $(11,12,13,14,15,16,17,18)$.

The main goal for clinician remains to best select patients for prophylactic surgery, since IPMN-derived invasive adenocarcinoma is usually associated with the same dismal prognosis than pancreatic adenocarcinoma. Today, despite several national and international guidelines, answers remain unperfect.

\section{What we used to believe andwhat we actually know and do not know...}

We used to artificially dichotomize the management of IPMN between main duct and branch duct IPMN, because of the results of early surgical series (Fig. 2). The cancer risk was at this time clearly overestimated (19). Nowadays, thanks to more than 20 years of clinical research, implications of high-volume centers and collaborative studies, we have refined the management of IPMN and better define indication for observation and surgery.

Numerous and sometime contradictory recommendations $(9,10,20,21)$ are available for clinicians, and there are mainly based on imaging features and clinical symptoms that are clearly imperfect and likely overestimate the risk of cancer occurrence (19). It is actually demonstrated that only a minority of IMPN are progressing to invasive lesions. If they try to be "evidence-based medicine», the quality of available study is poor for most of them, with no randomized controlled trial, very few prospective studies, and for most of them very few patients followed more than 10 years. Guidelines (Fig. 3) are quite consensual to select patient for surgery, i.e. patient with pancreatic adenocarcinoma or at very high risk to develop it. Patients with presence of jaundice, cytology positive for high-grade dysplasia or invasive cancer, with the presence of a contrastenhancing mural nodule ( $\geq 5 \mathrm{~mm}$ ), with MPD diame- 
Figure 2 - What we used to think and what we actually know

(C1 IPMN = main duct Pancreatic intraductal papillary mucinous neoplasms; C2 IPMN = branched duct Pancreatic intraductal papillary mucinous neoplasms)
What we used to think

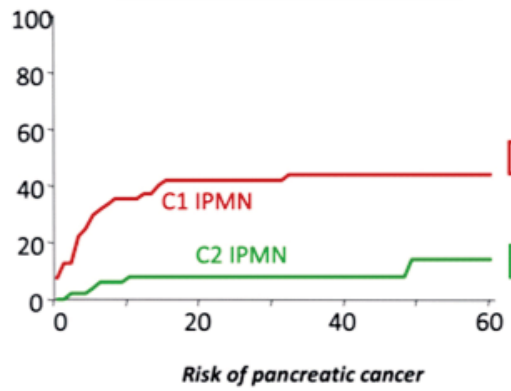

What we actually know
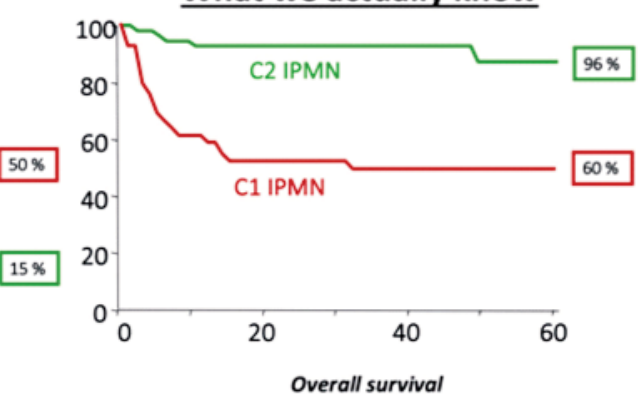

ter $>10 \mathrm{~mm}$ or solid mass should be considered as absolute indications for surgery as stated in international consensus. Recommendations are less consensual to select low-risk patients, i.e. patients with relative indications or "worrisome features". for whom the benefit risk balance between surgery and surveillance is clearly more delicate to appreciate, and it remains possible that too many prophylactic surgery is performed for lesions that would never progress to invasive lesions.

Nevertheless, several questions remain unaddressed, including the following ones:
- what is the risk of cancer progression - within the cyst but also in the whole pancreas - in followed patients $(22,23)$.

- How to best select patient for surgery?

- what is the risk of relapse after surgery?

- What should be the surveillance modality for non-operated patients and operated ones.

- Can follow-up be discontinued for selected cyst and patients?

- What will be, in a near future, the input of molecular or genomic analysis, in the diagnosis and selection for surgery of patients with IPMN.
Figure 3 - IPMN that need to be resected and IPMN that might be resected or observed according to International Association of Pancreatology (IAP)(10)and European guideline (9)
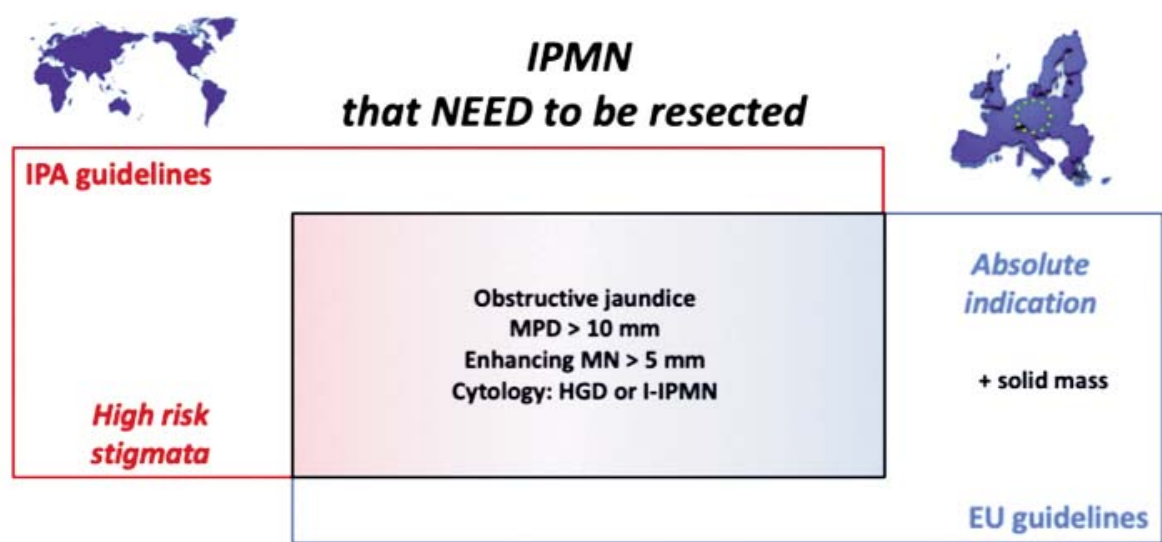

that MIGHT be resected / observed

\begin{tabular}{|c|c|c|}
\hline IPA guidelines & & \\
\hline $\begin{array}{l}\text { Thickening of cyst wall } \\
\text { Abrupt change in MPD } \\
\text { Lymphadenopathy } \\
\text { Growth }>5 \mathrm{~mm} / 2 \text { year } \\
\text { Cyst }>3 \mathrm{~cm} \\
\text { Worrisome } \\
\text { Features }\end{array}$ & $\begin{array}{c}\text { Pancreatitis } \\
\text { Enhancing } \mathrm{MN}<5 \mathrm{~mm} \\
\text { MPD } 5-9 \mathrm{~mm} \\
\text { Elevated Ca } 19-9 \text { levels }\end{array}$ & $\begin{array}{c}\text { Relative } \\
\text { indication } \\
+ \text { Diabetes } \\
\text { Growth }>5 \mathrm{~mm} / 1 \text { year } \\
\text { Cyst }>4 \mathrm{~cm}\end{array}$ \\
\hline
\end{tabular}




\section{The new fear... the distant cancer}

It has been proposed that IPMN represents a field defect, characterized by whole gland ductal instability (24). As such, the theoretical risk of developing carcinoma may not be limited the radiographicallyidentifiable target cyst, but rather applicable to the entire gland including regions separate from the initially identified target cyst. This "whole gland" risk, though, remains poorly defined as most studies have been limited to surgical series of patients who have undergone resection of the most radiographically concerning regions of the gland.

\section{CONCLUSION}

The best cancer is the one that never appears... and this justify pancreatic prophylactic surgery for IPMN, but of course not for all IPMN. Clear progresses have been made over the last decades, especially with recommendations and frequent actualization.

Nevertheless, several questions remain unanswered, and only large long-term international medico-surgical collaboration will allow to answer them.

\section{Conflict of interest}

The author has any financial or other kinds of personal conflicts of interest.

\section{REFERENCES}

1 Kromrey ML, Bulow R, Hubner J, Paperlein C, Lerch MM, Ittermann $\mathrm{T}$, et al. Prospective study on the incidence, prevalence and 5-year pancreatic-related mortality of pancreatic cysts in a populationbased study. Gut 2018;67:138-45

2 Salvia R, Malleo G, Marchegiani G, Pennacchio S, Paiella S, Paini M, et al. Pancreatic resections for cystic neoplasms: from the surgeon's presumption to the pathologist's reality. Surgery 2012;152:S135-42.

3 Gooiker GA, Lemmens VE, Besselink MG, Busch OR, Bonsing BA Molenaar IQ, et al. Impact of centralization of pancreatic cancer surgery on resection rates and survival. Br J Surg 2014;101:1000-5.

4 Gooiker GA, van Gijn W, Wouters MW, Post PN, van de Velde CJ, Tollenaar RA, et al. Systematic review and meta-analysis of the volume-outcome relationship in pancreatic surgery. Br J Surg 2011; 98:485-94.

5 Ahola R, Siiki A, Vasama K, Vornanen M, Sand J, Laukkarinen J. Effect of centralization on long-term survival after resection of pancreatic ductal adenocarcinoma. Br J Surg 2017.

6 Cameron JL, Riall TS, Coleman J, Belcher KA. One thousand consecutive pancreaticoduodenectomies. Ann Surg 2006;244:10-5.

7 Distler M, Kersting S, Niedergethmann M, Aust DE, Franz M, Ruckert
F, et al. Pathohistological subtype predicts survival in patients with intraductal papillary mucinous neoplasm (IPMN) of the pancreas. Ann Surg 2013;258:324-30.

8 Furukawa T, Hatori T, Fujita I, Yamamoto M, Kobayashi M, Ohike $\mathrm{N}$, et al. Prognostic relevance of morphological types of intraductal papillary mucinous neoplasms of the pancreas. Gut 2011; 60:509-16.

9 Pancreas ESGoCTot. European evidence-based guidelines on pancreatic cystic neoplasms. Gut 2018;67:789-804.

10 Tanaka M, Fernandez-Del Castillo C, Kamisawa T, Jang JY, Levy $P$, Ohtsuka T, et al.Revisions of international consensus Fukuoka guidelines for the management of IPMN of the pancreas. Pancreatology 2017;17:738-53.

11 Bernard P, Scoazec JY, Joubert M, Kahn X, Le Borgne J, Berger F, et al. Intraductal papillary-mucinous tumors of the pancreas: predictive criteria of malignancy according to pathological examination of 53 cases. Arch Surg 2002;137:1274-8.

12 Conlon KC. Intraductal papillary mucinous tumors of the pancreas. Journal of clinical oncology : official journal of the American Society of Clinical Oncology 2005;23:4518-23.

13 Rodriguez JR, Salvia R, Crippa S, Warshaw AL, Bassi C, Falconi $\mathrm{M}$, et al. Branch-duct intraductal papillary mucinous neoplasms: observations in 145 patients who underwent resection. Gastroenterology 2007:133:72-9; quiz 309-10.

14 Salvia R, Crippa S, Falconi M, Bassi C, Guarise A, Scarpa A, et al. Branch-duct intraductal papillary mucinous neoplasms of the pancreas: to operate or not to operate? Gut 2007;56:1086-90.

15 Schmidt CM, White PB, Waters JA, Yiannoutsos CT, Cummings OW, Baker M, et al. Intraductal papillary mucinous neoplasms: predictors of malignant and invasive pathology. Ann Surg 2007;246:644-51; discussion 51-4.

16 Tanno S, Nakano Y, Koizumi K, Sugiyama Y, Nakamura K, Sasajima J, et al. Pancreatic ductal adenocarcinomas in longterm follow-up patients with branch duct intraductal papillary mucinous neoplasms. Pancreas 2010;39:36-40.

17 Sohn TA, Yeo CJ, Cameron JL, Hruban RH, Fukushima N, Campbell KA, et al. Intraductal papillary mucinous neoplasms of the pancreas: an updated experience. Ann Surg 2004;239:78897; discussion 97-9.

18 Sugiyama M, Izumisato $\mathrm{Y}$, Abe N, Masaki T, Mori T, Atomi Y. Predictive factors for malignancy in intraductal papillary-mucinous tumours of the pancreas. Br J Surg 2003:90:1244-9.

19 Crippa S, Bassi C, Salvia R, Malleo G, Marchegiani G, Rebours V, et al. Low progression of intraductal papillary mucinous neoplasms with worrisome features and high-risk stigmata undergoing non-operative management: a mid-term follow-up analysis. Gut 2017;66:495-506.

20 Falconi M, Crippa S, Chari S, Conlon K, Kim SW, Levy P, et al. Quality assessment of the guidelines on cystic neoplasms of the pancreas. Pancreatology 2015;15:463-9.

21 Elta GH, Enestvedt BK, Sauer BG, Lennon AM. ACG Clinical Guideline: Diagnosis and Management of Pancreatic Cysts. Am J Gastroenterol 2018:113:464-79.

22 Marchegiani G, Mino-Kenudson M, Ferrone CR, Morales-Oyarvide V, Warshaw AL, Lillemoe KD, et al. Patterns of Recurrence After Resection of IPMN: Who, When, and How? Ann Surg 2015;262: 1108-14.

23 Lawrence SA, Attiyeh MA, Seier K, Gonen M, Schattner M, Haviland DL, et al.Should Patients With Cystic Lesions of the Pancreas Undergo Long-term Radiographic Surveillance?: Results of 3024 Patients Evaluated at a Single Institution. Ann Surg 2017;266:536-44.

24 Hruban RH, Takaori K, Canto M, Fishman EK, Campbell K, Brune K, et al. Clinical importance of precursor lesions in the pancreas. Journal of hepato-biliary-pancreatic surgery 2007;14:255-63. 